\title{
Motivational conflict and prosocial behaviour of kindergarten children
}

Gisela Trommsdorff \& Wolfgang Friedlmeier 
The present study aims to clarify the role of different emotions for children's prosocial behaviour on the basis of a motivation-theoretical approach. Specifically, the functions of empathy and distress with respect to prosocial behaviour were investigated in two different experimental situations. Fiveyear-old girls $(N=50)$ participated in two observation studies. In study 1 the girls were randomly assigned: (a) to a nondistraction condition by experiencing another person's misfortune $(N=13)$; or $(b)$ to a distraction condition by inducing achievement motivation. In study 2 the girls $(N=25)$ underwent the same procedure as in the nondistraction condition in order to check the cross-validation of the variables measured. The girls' videotaped nonverbal reactions (quality of facial expression and focus of attention) as well as the intensity of helping were analysed. The cross-validation was successful. The two experimental conditions did not differ with respect to empathy, distress, and helping. However, the relation between empathy and distress pointed at different directions with regard to the results of the two experimental groups. Furthermore, the positive effect of empathy as well as the negative effect of distress on prosocial behaviour were eliminated in case of the distraction situation. The measures on focus of attention supplemented the understanding of these different reactions in the two experimental conditions. The results are discussed in a motivation-theoretical framework by taking into account processes of emotion regulation.

The aim of the present study is to analyse the functions of emotions for prosocial behaviour on the basis of a motivation-theoretical approach. For several decades, research on prosocial behaviour has focused on cognitive factors (expectations and values) neglecting the role of emotions (for a summary, see Bierhoff, 1990; Staub, 1986). Considering the fact that infants display prosocial behaviour even though they lack cognitive abilities such as perspective taking (cf. Radke-Yarrow, Zahn-Waxler, \& Chapman, 1983; Zahn-Waxler \& Radke-Yarrow, 1982), one may assume an emotional basis for prosocial behaviour. However, emotional contagion 
which can be observed in newborns (Sagi \& Hoffman, 1976) is not the same as empathy and not yet a basis for prosocial motivation. The development of a self-schema (Bischoff-Köhler, 1990) is considered as a necessary condition for empathy and for the development of prosocial motivation: it is the self-other differentiation which allows the child to identify partially with the other person. Thereby, empathy (sympathy) can arise and induce prosocial goals. Nevertheless, the process of contagion remains an important basis for empathy whereas perspective-taking as a cognitive ability becomes effective at a later developmental age and cannot be seen as a necessary condition for empathy.

Empathy (often called "sympathy", cf. Eisenberg, McCreath, \& Ahn, 1988) is understood here as feeling with the other person and partially identifying with him/her. From a motivation theoretical point of view empathy is a necessary condition for altruistically motivated prosocial behaviour (cf. Hoffman, 1984). Several empirical studies on children in the United States (Eisenberg et al., 1988; Zahn-Waxler, Radke-Yarrow, \& King, 1979), in Germany (Friedlmeier, 1993; Trommsdorff, 1993), and also in other cultures (Kienbaum, 1993; Kobayashi, 1995; Trommsdorff, 1995) have supported this viewpoint. As Staub (1986) has pointed out, the specific emotional quality which precedes prosocial behaviour enables us to differentiate between altruistic and egoistic prosocial behaviour. This theorising underlies the studies on the effects of empathy and distress on prosocial behaviour. Several studies have shown that not only empathy but other emotions such as distress can be activated in a situation when observing the misfortune of another person. Distress is a feeling of uneasiness and irritation. Whether both-empathy and distress-can induce prosocial behaviour is unclear in the literature (Batson, Fultz, \& Schoenrade, 1987; Cialdini et al., 1987). Studies on adults have shown a positive relation between distress and prosocial behaviour in situations that the person could not escape easily (cf. Batson \& Oleson, 1991; Cialdini et al., 1987). In contrast, our studies on children have demonstrated a negative relation between distress and prosocial behaviour (Friedlmeier, 1993; Kienbaum, 1993; Trommsdorff, 1993, 1995). In these studies, the level of escape conditions was not varied; nevertheless, we assume that the situation was structured (and subjectively perceived) as a noneasy escape condition due to the asymmetric relationship between the child and the adult playmate. The negative relationship between distress and prosocial behaviour in our studies with children contradicts the results of studies carried out with adults. In childhood, empathy seems to foster prosocial behaviour whereas distress as a negative emotional reaction blocks prosocial behaviour in noneasy escape conditions.

One reason for these age-related differences in regard to the relationship between distress and prosocial behaviour may consist in the fact that 
children's ability of emotion regulation is different compared to adults. In line with the reasoning of Eisenberg et al. (1994) it is assumed here that processes of emotion regulation have to be taken into account when studying the possible impact of empathy and distress on prosocial behaviour. Emotion regulation functions as an intervening process which allows for coping with distress when witnessing the sadness or the misfortune of another person. In early childhood, parents are external regulators of their children's emotional reactions. The child's ability of emotion regulation develops by internalising former experiences of such interactive regulations (cf. Friedlmeier \& Trommsdorff, 1998; Thompson, 1994). Therefore, adults have more effective strategies available to regulate the experience of distress than children have, and prosocial behaviour is more probable in cases of distress if the person is able to regulate his/her emotions sufficiently (cf. Eisenberg et al., 1994). A second reason that may explain age-related differences can be derived from the first one. The lack of effective strategies itself may cause distress. An empathic concern followed by the lack of competence (i.e. the child wants to help but does not know how to do), may also cause a distress reaction. Whereas adults' distress is often characterised as a self-focused emotional reaction (e.g. Batson, 1991), children's distress can also be described as an other-focused emotional reaction. Blocked prosocial behaviour caused by incompetence may lead to distress and distress may block prosocial behaviour. A reciprocal influence can be assumed. Therefore, we expect more prosocial behaviour of preschool children in case of empathy and less in case of distress. Accordingly, a positive relation between empathy and prosocial behaviour and a negative relation between distress and prosocial behaviour is expected for preschool children.

In case of distress, children may have less strategies available to ignore the situation, or to distract their attention from the distressing stimulus. The level of negative arousal cannot be reduced, prosocial behaviour is blocked, and the latter may strengthen the negative emotional state. Consequently, if children get an opportunity to distract themselves from a distressing situation they could display more prosocial behaviour. The induction of distractions for the child could serve as a means to facilitate emotion regulation in the following way: distracting stimuli may reduce the emotional involvement and/or the extent of identification with the other person's sadness and this may support the emergence of prosocial motivation and behaviour. Such induced distraction creates an easy escape condition that can be compared to a noneasy escape condition that was used in most of the studies with children. Therefore, the research design here is similar to the studies with adults (cf. Batson, 1991, 1997). Such design was not applied to studies with children so far. Accordingly, the following questions will be studied here. (1) Do children display less 
distress and less empathy in the distraction situation compared to the nondistraction situation? (2) Does the distraction situation affect the intensity of prosocial behaviour in a different way compared to the nondistraction situation? (3) Does the distraction situation affect the relationships between emotional reactions and prosocial behaviour in a different way compared to the nondistraction situation?

The induction of distraction as one experimental condition can be realised by creating a situation, in which children do not only experience another person's sadness but also they are confronted with a task which has to be finished in a limited amount of time in order to obtain a reward at the same time. The induction of an egoistic motivation in such a situation should create a motivational conflict that provides a variety of opportunities to modulate the emotional reaction evoked by the other person's sadness. The experience of another person's sadness without distraction may also create a motivational conflict between prosocial and egoistic motivation (e.g. a conflict between the wish to help and the high costs), but this motivational conflict remains related to the situation. In the case of induced achievement motivation, the egoistic motivation directs the child's attention to the task that is unrelated to the sad person's situation. Only in this sense the egoistic motivation may function as a distraction stimulus.

To summarise, the goal of the present study is to investigate the relations between emotional experiences and prosocial behaviour in two different situations. In the nondistraction situation children are confronted with the other person's sadness whereas in the distraction situation an achievement motivation is induced. Children's reactions are observed in these two situations which are both structured according to quasi-natural settings. These observations are based on several measures: the quality of facial expressions allows to measure empathy and distress; the focus of attention indicates the extent to which the child is concentrating on the victim or other objects. Intensity of helping is used here as a refined indicator of prosocial behaviour.

\section{METHOD}

\section{Sample and Procedures}

Five-year-old girls $(N=50, M=60.28$ months, $\mathrm{SD}=2.83$ months $)$ from kindergartens in Konstanz participated in the two studies. The mothers of the girls were contacted via kindergarten teachers. They all have given permission for their daughters to participate in the study. In the first study, $N=25$ girls were randomly assigned to one of two experimental conditions; in the second study $N=25$ girls were observed in the nondistraction situation for reasons of cross-validation. There was no difference between the samples with respect to socioeconomic status, birth 
order, or family size. The majority of the mothers had about the same educational level (Abitur), and the majority of the mothers were housewives.

The studies took place in the kindergartens. First, a dyadic interaction between the child and the experimenter (a female playmate, about 20 years old) took place which served as a warning-up session. Then the subject and the playmate started a "balloon-play", they changed two coloured balloons into balloon-dolls. Each, the child and the playmate painted and dressed their own balloon-doll, gave them faces and names, and had the dolls play with each other. Then each child was randomly assigned to one of the following conditions:

Distraction situation. $N=12$ girls were asked to build a tower for the balloon (using wooden blocks) within 3 minutes in order to get a reward which they had chosen at the beginning of the session. The running time was indicated by large hourglass in front of the child.

Nondistraction situation I. $N=13$ girls underwent the same procedure as the foregoing by being requested to build the tower but without limiting the amount of time and without giving a present.

Nondistraction situation II. $N=25$ girls were observed under same conditions as described in the foregoing in order to test the validity of the nondistraction situation. This control group was studied one year later, and the playmate was not the same as in the first study.

In the distraction and nondistraction situations, the following experimental procedure took place: At a suitable moment when the child was concentrating on the tower, the playmate popped her balloon secretly, displayed a sad reaction, and fell into a state of sorrow for about two minutes. After getting a signal from outside the playroom, the playmate calmed down and played with the child relaxed and cheerfully for another couple of minutes. In the end, all children received the same kind of small gift. The scenario was videotaped by two cameras. One camera filmed the entire scene, whereas the second focused on the child for a better recording of her nonverbal reactions.

\section{Measures}

The videotapes were analysed with respect to the intensity of the subjects' achievement motivation, focus of attention, emotional reactions, and helping behaviour.

Achievement Motivation. This was rated on a 6-point scale ranging from $0=$ very low motivation (no tension; the child interrupts very 
frequently; the child does not comment on the task at all) to $6=$ very high motivation (high tension; the child acts very quickly, even hectically; she comments on her task and related activities).

Emotional Reactions. Empathy and Distress were evaluated according to the strength of expression on 6-point scales ranging from $0=$ no reaction to $6=$ strong emotional reaction. The criteria used for the evaluations were similar to those used by Eisenberg et al. (1988) as well as those used in our research group (Trommsdorff, Friedlmeier, \& Kienbaum, 1991).

Empathy was coded when the child interrupted her activity, her eyes blinked slowly, she lowered her head, the lower part of her face was relaxed, and when she was oriented towards the playmate and her misfortune.

Distress was coded when the lower part of the child's face was tense; her lips were pressed together; nervous movements of the mouth and nervous gestures occurred.

A validation of the measures of emotional reactions has been carried out by Kienbaum and Trommsdorff (1997) by using another situation-specific verbal test.

Focus on Victim and Focus on Objects. Two different focuses of attention were measured. Focus on Victim: The amount of time the child focused on the playmate and the popped balloon. Focus on Objects: The amount of time the child focused on other objects, like the tower, wooden blocks, or her own balloon. For both variables, the time spent focusing in relation to the total length of time was calculated.

Intensity of Helping. This was based on a global evaluation on a 6-point scale ranging from " 0 " (no helping behaviour) to "5" (high-intensity helping behaviour). Examples: If the child only gave one short suggestion and did not help the playmate otherwise, a low intensity of helping $(=1)$ was rated. If the child tried to help the playmate a great deal (e.g. by looking around for another balloon or offering her own balloon as a substitute), high intensity $(=5)$ was rated.

\section{Inter-rater Reliability}

For each study four trained independent coders evaluated the tapes in the following way: Achievement Motivation, Emotional Reactions, and Focus of Attention were coded by coders 1 and 2. Intensity of helping was rated by coders 3 and 4 in order to control a subjective bias in regard to the relation between emotional reaction and prosocial behaviour. In study 1 , 
TABLE 1

Inter-rater Reliabilities of the Variables Coded in Studies 1 and 2 (Spearman Rank)

\begin{tabular}{|c|c|c|}
\hline & $\begin{array}{c}\text { Study } 1 \\
(n=12) \\
r_{\mathrm{s}(10)}\end{array}$ & $\begin{array}{c}\text { Study } 2 \\
(n=25) \\
r_{\mathrm{s}(10)}\end{array}$ \\
\hline Achievement Motivation & $.89 * * *$ & $.82 * * *$ \\
\hline \multicolumn{3}{|l|}{ Emotional Reaction } \\
\hline Empathy & $.93 * * *$ & $.92 * * *$ \\
\hline Distress & $.87 * * *$ & $.92 * * *$ \\
\hline \multicolumn{3}{|l|}{ Focus of Attention } \\
\hline Victim & $.97 * * *$ & $.97 * * *$ \\
\hline Objects & $.95 * * *$ & $.99 * * *$ \\
\hline \multicolumn{3}{|l|}{ Helping } \\
\hline Intensity & $.71 *$ & $.90 * * *$ \\
\hline
\end{tabular}

coders 2 and 4 evaluated half of the sample $(n=12)$, in study 2 they evaluated the whole sample. Spearman rank correlations were used to compute the reliability coefficients. The results showed a sufficiently high agreement for all variables in both studies (see Table 1). Disagreements were solved by discussion between the raters and agreement under the supervision of a third rater.

\section{Data Analyses}

The following analyses concentrate on differences between the two experimental conditions-the distraction and the nondistraction situation. However, the two nondistraction groups will be kept separate in order to test the validity of the measured variables and their relations at the same time. After testing for differences between the variables of the three groups by using ANOVA, correlations were computed. Due to the small number of subjects we refrained from assuming interval level; therefore, Spearman rank correlations were computed. Partial correlations among the different emotional reactions as well as between each of the emotional reactions and prosocial behaviour were computed by controlling for the variable "Achievement Motivation" in order to test whether this variable had influenced these relations. As no specific differences occurred as compared to the correlations without controlling, the results of the partial correlations are not reported here. Finally, comparisons between correlations were computed by using $z$-values. They will only be reported in case of high relevance with regard to the theoretical questions. 


\section{RESULTS}

\section{Situational Differences between Distraction and Nondistraction Situations}

Achievement Motivation. As expected, significant differences with respect to the degree of Achievement Motivation were found $[F(2,47)=12.19, P<.001]$. Girls in the distraction situation displayed more Achievement Motivation $(M=3.67, \mathrm{SD}=1.61)$ as compared to those in the nondistraction situation I $(M=1.92, \mathrm{SD}=0.95)$ and nondistraction situation II $(M=1.72, \mathrm{SD}=0.98)]$.

Focus of Attention. Girls in the distraction as compared to those in the two nondistraction situations focused significantly less frequently on the victim and more frequently on other objects (see Table 2). These results clearly demonstrate that our experimental induction of distraction was successful, and that the situation was really serving as distraction.

Emotional Reactions and Helping Behaviour. There was no difference in the intensity of the empathic reactions (when observing the sadness of the playmate) in the two situations (see Table 2); the intensity of distress was somewhat less intense in the distraction as compared to the nondistraction situations, but the difference was not significant. No significant differences in Intensity of Helping were found in the comparison of the two situations (see Table 2).

\section{TABLE 2}

Comparison of Emotional Reaction, Focus of Attention, and Helping in Distraction and Nondistraction Situations

\begin{tabular}{lcccc}
\hline & $\begin{array}{c}\text { Distraction } \\
\text { Situation } \\
(n=12)\end{array}$ & $\begin{array}{c}\text { Nondistraction } \\
\text { Situation I } \\
(n=13)\end{array}$ & $\begin{array}{c}\text { Nondistraction } \\
\text { Situation II } \\
(n=25)\end{array}$ & F-values \\
& $M(\mathrm{SD})$ & $M(\mathrm{SD})$ & $M(\mathrm{SD})$ & \\
\hline Emotional Reaction & & & & \\
Empathy & $1.58(1.08)$ & $2.00(1.58)$ & $2.12(1.51)$ & $<1.00$ \\
Distress & $0.88(1.05)$ & $1.35(1.28)$ & $1.52(1.15)$ & 1.25 \\
Focus of Attention & & & & \\
Victim & $32.77^{a}(18.30)$ & $62.23^{b}(18.28)$ & $51.08^{b}(21.32)$ & $6.99^{* * *}$ \\
Objects & $56.92^{a}(16.98)$ & $27.85^{b}(19.69)$ & $24.08^{b}(26.25)$ & $8.87^{* * *}$ \\
Helping & & & & \\
Intensity & $1.42(0.90)$ & $1.69(1.75)$ & $2.24(1.85)$ & 1.15 \\
\hline
\end{tabular}

Note: Means with same superior letter do not differ significantly.

$* * P<.01, \quad * * * P<.001$. 


\section{Relations between Achievement Motivation and Emotional Reactions}

Correlations between Empathy and Achievement Motivation were nonsignificant negative for both situations [distraction situation: $r_{\mathrm{s}}(10)=-45$, n.s.; nondistraction situation I: $r_{\mathrm{s}}(11)=-.22$, n.s.; nondistraction situation II: $r_{\mathrm{s}}(23)=-.26$, n.s.]. The correlations between Distress and Achievement Motivation also yielded nonsignificant negative relations [distraction situation: $r_{\mathrm{s}}(10)=-.27$, n.s.; nondistraction situation I: $r_{\mathrm{s}}(11)=-.25$, n.s.; nondistraction situation II: $\left.r_{\mathrm{s}}(23)=-.12\right]$.

\section{Relations between Emotional Reactions}

In the distraction situation, Empathy and Distress tended to correlate positively $\left[r_{\mathrm{s}}(10)=.25\right.$, n.s. $]$, they correlated negatively in the nondistraction situations [I: $r_{\mathrm{s}}(11)=-.39$, n.s.; II: $r_{\mathrm{s}}(23)=-.29$, n.s.]. The difference in the correlations between Empathy and Distress for the two conditions was not significant [I: $z=1.40$, n.s.; resp. II: $z=1.37$, n.s.].

\section{Relations between Emotional Reactions and Helping Behaviour}

Situational differences with respect to the relation between Empathy and Intensity of Helping were found. Positive correlations were only found in the nondistraction situations [I: $r_{\mathrm{s}}(11)=.74, P<.01 ; \mathrm{II}: r_{\mathrm{s}}(23)=.61$, $P<.01]$ but not in the distraction situation $\left[r_{\mathrm{s}}(10)=-.01\right]$ (see Table 3 ). The difference of the correlations between Empathy and Intensity of Helping in the two situations was significant [I: $z=1.97, P<.05$; resp. II: $z=1.76, P<.10]$. A similar but less stronger pattern appeared with regard to the relations between Distress and Intensity of Helping: Significant negative relation between Distress and Intensity of Helping in the nondistraction situations appeared again [I: $r_{\mathrm{s}}(11)=-.64, P<.05$; II: $\left.r_{\mathrm{s}}(23)=-.44, P<.05\right]$, whereas the correlation in the distraction situation was only tendentially significant $\left[r_{\mathrm{s}}(10)=-.54, P<.10\right]$. Therefore, no differences between the correlations in these two situations could be demonstrated.

\section{Relations between Emotional Reactions and Focus of Attention}

In the nondistraction situation $\mathrm{I}$, the extent of empathy correlated significantly negatively with Focus on Objects [I: $r_{\mathrm{s}}(11)=-.80$, $P<.001]$, whereas in the distraction condition Empathy correlated significantly positively with Focus on Victim $\left[r_{\mathrm{s}}(10)=.66, P<.05\right]$. However, the results in the nondistraction situation II did not support 
TABLE 3

Correlations Between Emotional Reaction, Focus of Attention, and Helping in Distraction and Nondistraction Situations I and II (Spearman Rank)

\begin{tabular}{lcccc}
\hline $\begin{array}{l}\text { Distraction Situation }(n=12) \\
\text { Nondistraction Situation I }(n=13)\end{array}$ & Distress & $\begin{array}{c}\text { Focus } \\
\text { on } \\
\text { Nondistraction Situation II }(n=25)\end{array}$ & $\begin{array}{c}\text { Focus } \\
\text { on } \\
\text { Objects }\end{array}$ & $\begin{array}{c}\text { Intensity } \\
\text { of }\end{array}$ \\
\hline Empathy & .25 & $.66^{*}$ & -.36 & -.01 \\
& -.39 & $.58+$ & $-.80^{* * *}$ & $.74^{* *}$ \\
& -.29 & $.39+$ & -.21 & $.61^{* *}$ \\
Distress & & $.58^{*}$ & -.40 & $-.54+$ \\
& & -.34 & .28 & $-.64^{*}$ \\
Focus on Victim & & -.08 & .00 & $-.44^{*}$ \\
& & & $-.73^{* *}$ & -.14 \\
& & & $-.72^{* *}$ & .28 \\
Focus on Objects & & & & $.33+$ \\
& & & & $-.76^{* * *}$ \\
\end{tabular}

$+P<.10, * P<.05, * * P<.01, * * * P<.001$.

the strong correlation found in nondistraction situation $\mathrm{I}\left[r_{\mathrm{s}}(23)=-.21\right]$. In contrast to the relation between Empathy and Focus of Attention, the relations between Distress and the Focus of Attention yielded a clearer inverse pattern for the two situations because the coefficients pointed to different directions: The more children reacted with distress the less children of the distraction group focused on the task-related objects $\left[r_{\mathrm{s}}(10)=-.40, \mathrm{n} . \mathrm{s}.\right]$ and the more they focused on the victim $\left[r_{\mathrm{s}}(10)=.58\right.$, $P<.05]$. Girls of the two nondistraction groups did not show any relation between both variables [Focus of Objects: $r_{\mathrm{s}}(11)=.28$, n.s.; resp. $r_{\mathrm{s}}(23)=.00$, n.s.; Focus on Victim: $r_{\mathrm{s}}(10)=-.34$, n.s.; resp. $r_{\mathrm{s}}(23)=-.08$, n.s.].

\section{Relations between Helping Behaviour and Focus of Attention}

The relation between Focus of Attention and Intensity of Helping yielded a different pattern for the two experimental conditions: There was a tendency that the more children focused on the victim in the nondistraction situation the stronger was their helping behaviour [I: $r_{\mathrm{s}}(11)=.28$, n.s.; $\left.r_{\mathrm{s}}(23)=.33, P<.10\right]$; in the same vein, the more they focused on the taskrelated object the weaker was their helping behaviour [I: $r_{\mathrm{s}}(10)=-.56$, $P<.05$; II: $r_{\mathrm{s}}(23)=-.32$, n.s.] (see Table 3$)$. No such relation occurred for 
the children in the distraction situation and the comparison of the correlations between the experimental groups yielded even one significant difference for the correlation between Focus on Objects and Intensity of Helping for distraction and nondistraction situation $\mathrm{I}[z=1.73, P<.10]$.

To summarise the results, no significant differences occurred between the two nondistraction situations. In regard to the two experimental conditions, emotional reactions-Empathy and Distress-and Helping did not differ in the two situations. The correlation between Empathy and Distress tended to be positive in the distraction situation, and a negative tendency occurred in the nondistraction situations. In the nondistraction situations, positive relations between Empathy and Helping and negative relations between Distress and Helping were found. These results were not found in the distraction situation in which neither the extent of empathic reactions nor distress was related to helping behaviour in a significant way. The diverse measures on focus of attention supplemented the results on different reactions in the two experimental conditions.

\section{DISCUSSION}

At first glance, the two experimental conditions (distraction and nondistraction situations) did not differ: Children displayed similar intensities of empathy, distress, and prosocial behaviour in both situations. One may conclude that independent of the induction of conflicting motivations or alternative goals, preschool children either react with empathy or with distress, and they help at the same level of intensity. However, only focusing on lacking differences between mean scores in these two experimental situations leads to incorrect conclusions as situational and individual differences are clouded. Note, our main interest was to study the functions of emotional reactions with respect to helping (i.e. on the one hand, the relation between distress and prosocial behaviour, and on the other, the relation between empathy and prosocial behaviour. In this respect, there were clear differences between the two experimental situations.

The main results showed that empathy was fostering and distress was hindering prosocial behaviour in the nondistraction situation, whereas this was not the case in the distraction situation where achievement motivation was induced as a means to provide for distraction from distress or empathy. In the nondistraction condition, the expected patterns of relations occurred. Here, empathy is an important condition for prosocial behaviour, whereas - different from results in the literature on distress and helping (e.g. Batson, 1991, 1997) — distress obviously blocks prosocial behaviour of the preschool girls studied here. The present results of the 
negative function of distress for prosocial behaviour are in line with those of our previous studies with children (Friedlmeier, 1993; Kobayashi, 1995; Trommsdorff, 1995). The discrepancy between our results on preschool children and the studies with adults may be due to age-related differences of emotion regulation as already explained at the beginning of the paper. The girls have less effective strategies available in order to regulate the distress. The lack of knowing what to do may be a further cause of distress. Therefore, it may also be possible that adults experience a different quality of negative emotions when witnessing the sadness of another person as children do. These results underline the importance of taking into account the role of developmental conditions like emotion regulation. So far, this question of developmental conditions for the relation between empathy, distress, and prosocial behaviour has not received much attention and cannot yet be answered on the basis of developmental studies. Future studies should focus on the role of emotion regulation abilities and their development when studying relations between empathy, distress, and prosocial behaviour.

In contrast to the nondistraction situation, neither the positive relation between empathy and prosocial behaviour, nor the negative relation between distress and prosocial behaviour were significant in the distraction situation. These results indicate that the functions of empathy and distress for helping depend on the situation. Our explanation of these differences stems from the idea that the emotional reaction of distress displayed in the distraction condition may have different causes as compared to the negative emotion displayed in the nondistraction situations. This interpretation will be outlined by including further empirical results.

First, reverse relations between distress and empathy were yielded in the two situations. Whereas in the nondistraction situation the extent of empathy reduced the extent of distress and vice versa, even a tendentially positive relation occurred in the distraction situation. Obviously, the experience of empathy does not preclude irritation (or some kind of negative emotional experience) but rather increases the probability of an emerging distress reaction in the distraction situation. The distress may be caused by the conflicting motivational tendencies which have been induced in our study, namely, empathic feeling and altruistic motivation versus achievement motivation and building the tower. Therefore, in case of an empathic reaction the occurrence of a distress reaction caused by the egoistic motivation may decrease the intensity of helping. At the same time, the experience of strong distress as reaction to the playmate's sadness combined with the egoistic motivation did not lead to a stronger distress reaction but rather the distraction stimulus worked as a means to reduce distress, and even an empathic expression emerged. In this sense, the induced achievement goal fulfils the function of an easy escape condition 
that allows to interrupt the blocked behaviour which is characteristic for children who react with distress in the nondistraction group. This interpretation leads to the conclusion that an easy escape condition based on distraction stimuli reduces the relationship between emotional reactions and prosocial behaviour for preschool children. In general, emotional reactions like empathy and distress vary in their meaning for resulting prosocial behaviour in regard to the situation, the person, and the respective appraisal processes which may affect the experience and the regulation of the specific emotion differently (cf. Friedlmeier \& Trommsdorff, 1998; Raver, 1996; Trommsdorff \& Friedlmeier, 1998).

Second, the results on the focus of attention showed different patterns of emotional reactions and focus of attention in the two experimental situations. In the nondistraction group a positive relationship between empathy and focus on victim and a negative relationship between empathy and focus on objects appeared whereas the relations between distress and focus of attention pointed to the opposite direction but were no more significant. The lack of significant correlation may base on the fact that two forms of distress that can not be differentiated at the observational level lie behind these results: self-focused distress (i.e. the child avoids the contact to the sad person and wants to leave the room whenever possible), and other-focused distress (i.e. the child is oriented to the sad playmate but the passivity leads to and maintains a distress reaction). According to these different causes of distress, an inverse pattern of these two forms is expected in regard to the relationship with focus of attention. Only the self-focused distress should point to the opposite direction as compared to empathy.

In contrast to the nondistraction group, the correlations between empathy and focus of attention and between distress and focus of attention pointed at the same direction in the distraction group: A positive relationship between emotional reaction and focus on victim and a negative relationship between emotional reaction and focus on objects were yielded. Whereas the patterns with empathy are similar to the results of the nondistraction group, the patterns with distress have to be explained further. The focus on objects presumably orients the child to the achievement task including the induced egoistic goal. The egoistic goal loses its salience if the altruistic goal of helping the victim predominates. Their stronger focus on the person while experiencing distress can be interpreted in the way that they achieve a certain psychological and emotional distance which is provided by the competing altruistic and achievement motivations. As the relation between distress and prosocial behaviour is less negative compared to the nondistraction group, we can conclude that these competing motivational tendencies seem to facilitate the display of prosocial behaviour but in a limited way. Therefore, the 
same kind of focus of attention in the two experimental settings has different functions: Reducing or increasing distress. This interpretation is based on the assumption that differently caused reactions of distress are functionally related to a specific focus of attention and the related ability to regulate distress. As our present analyses are only based on correlation data, causal questions cannot be answered here. Future research should clarify the role of focus of attention for the regulation of distress.

The relations between focus of attention and prosocial behaviour also yielded a different pattern in regard to the two experimental conditions: In the nondistracting condition, the focus on the victim was related to more intensive helping; and focus on objects clearly reduced the intensity of helping. In the distraction situation, no relations between focus of attention and helping appeared. A specific focus may indicate the activation or deactivation of prosocial behaviour only if further conflicting motives and (related) distress reactions are not present.

We have tried to overcome some deficits of past research on prosocial motivation by creating a natural environmental setting, by carrying out observations of actual behaviour, and by analysing helping behaviour in a more refined way than it is usually the case in other research on prosocial behaviour. We have invested much effort by studying the quality of prosocial behaviour (intensity) and not only measuring either verbal responses or just measuring whether prosocial behaviour has occurred or not. Nevertheless, several methodological shortcomings have to be mentioned. First the sample size of study 1 was quite small. This was due to the extended and elaborated procedures employed in the experiments. In order to control whether the small sample size in study 1 has affected these results, we carried out a second study using the same design as in the nondistraction situation of study 1 . Most of the results of the nondistraction group of study 1 could be confirmed except two correlations. Therefore, in general, the cross-validation can be evaluated as successful. Another shortcoming is that the present study was only carried out with girls. This was due to the fact that controlling for gender would have required to double the sample size. As the present study did not address questions of possible gender differences in empathy, distress, and prosocial behaviour, we concentrated on controlling for the experimental procedures. However, in further research, possible gender differences should be studied for this specific age group. Furthermore, we did not overcome another methodological shortcoming in the study of prosocial motivation, namely, to measure the actual process of emotional reactions. The analyses of the overall intensity of specific emotional reactions should be complemented in the future by an analysis of the sequence of children's emotions preceding their actual (prosocial) behaviour; this would allow to gain more insight into inter-individual processes of emotion regulation. 


\section{Conclusions}

A first major contribution of this study was to clarify the role of emotions for prosocial motivation and prosocial behaviour in childhood. Here, a positive function of empathy was documented with regard to prosocial behaviour in a situation in which a child observes another person's misfortune. This finding represents further empirical support for the assumption of the functional value of empathy and prosocial behaviour. The negative function of distress with regard to prosocial behaviour also confirms the results of other studies with children but contradicts the positive function of distress found for adults if we assume that the children could not leave the situation easily. This age-related difference is explained by arguing that the causes of distress for children and adults vary due to different developmental levels of emotion regulation. A second major contribution was to test whether the opportunity to distract has specific effects on the functional meaning of the emotional reactions. The positive effect of empathy and the negative effect of distress on prosocial behaviour were eliminated in this group of girls. These results are also interpreted in terms of emotion regulation as an important mediator for internal processes. Thus, we are convinced that emotion regulation is not only an important concept to interpret and explain the results but also can be used to analyse the inter-individual processes of emotional reactions and related behaviour in more detail (cf. Friedlmeier \& Trommsdorff, 1998; Trommsdorff \& Friedlmeier, 1998). The ability of emotion regulation develops in early childhood and the concept may enable a better understanding of the origins of emotional experience and related development of social motivation and social behaviour.

\section{REFERENCES}

Batson, C.D. (1991). The altruism question: Toward a social psychological answer. Hillsdale, NJ: Erlbaum.

Batson, C.D. (1997). Self-other merging and the empathy-altruism hypothesis: Reply to Neuberg et al. Journal of Personality and Social Psychology, 73, 517-522.

Batson, C.D., Fultz, J., \& Schoenrade, P.A. (1987). Distress and empathy: Two qualitatively distinct vicarious emotions with different motivational consequences. Journal of Personality, 55, 19-39.

Batson, C.D., \& Oleson, K.C. (1991). Current status of empathy-altruism hypothesis. In M.S. Clark (Ed.), Prosocial behavior (pp.62-85). London: Sage. 
Bierhoff, H.W. (1990). Psychologie hilfreichen Verhaltens [Psychology of prosocial behaviour]. Stuttgart: Kohlhammer.

Bischof-Köhler, D. (1990). The development of empathy in infants. In M.E. Lamb \& H. Keller (Eds.), Infant development: Perspectives from German-speaking countries (pp.245273). Hillsdale, NJ: Erlbaum.

Cialdini, R.B., Schaller, M., Houlihan, D., Arps, K., Fultz, J., \& Beaman, A.L. (1987). Empathy-based helping: Is it selflessly or selfishly motivated? Journal of Personality and Social Psychology, 52, 749-758.

Eisenberg, N., Fabes, R.A., Murphy, B., Karbon, M. Maszk, P., Smith, M., O’Boyle, C., \& Suh, K. (1994). The relations of emotionality and regulation to dispositional and situational empathy-related responding. Journal of Personality and Social Psychology, 66, 776-797.

Eisenberg, N., McCreath, H., \& Ahn, R. (1988). Vicarious emotional responsiveness and prosocial behavior: Their interrelations in young children. Personality and Social Psychology Bulletin, 14, 298-311.

Friedlmeier, W. (1993). Entwicklung von Empathie, Selbstkonzept und prosozialem Handeln in der Kindheit [Development of empathy, self-concept, and prosocial behaviour in childhood]. Konstanz: Hartung-Gorre.

Friedlmeier, W., \& Trommsdorff, G. (1998). Emotion regulation in early childhood. A crosscultural comparison between German and Japanese toddlers. Manuscript submitted for publication.

Hoffman, M.L. (1984). Interaction of affect and cognition. In C.E. Izard, J. Kagan, \& R.B. Zajonc (Eds.), Emotions, cognition, and behavior (pp.103-131). Cambridge, UK: Cambridge University Press.

Kienbaum, J. (1993). Empathisches Mitgefühl und prosoziales Verhalten deutscher und sowjetischer Kindergartenkinder [Empathy and prosocial behaviour of German and Russian preschoolers]. Regensburg: Roderer.

Kienbaum, J., \& Trommsdorff, G. (1997). Vergleich zweier Methoden zur Erfassung des Mitgefühls im Vorschulalter [Comparison between two methods for measuring empathy in preschool age]. Zeitschrift für Entwicklungspsychologie und Pädagogische Psychologie, 29, 271-290.

Kobayashi, M. (1995). Selbstkonzept und Empathie im Kulturvergleich: Ein Vergleich deutscher und japanischer Kinder [Self-concept and empathy in cross-cultural psychology: A comparison between German and Japanese children]. Konstanz: Universitätsverlag.

Radke-Yarrow, M., Zahn-Waxler, C., \& Chapman, M. (1983). Children's prosocial dispositions and behavior. In P.H. Mussen (Ed.), Handbook of child psychology (pp.469-545). New York: Wiley.

Raver, C.C. (1996). Relations between social contingency in mother-child interaction and 2-year-olds' social competence. Developmental Psychology. 32, 850-859.

Sagi, A., \& Hoffman, M.L. (1976). Empathic distress in the newborn. Developmental Psychology, 12, 175-175.

Staub, E. (1986). A conception of the determinants and development of altruism and aggression: Motives, the self, and the environment. In C. Zahn-Waxler, E.M. Cummings, \& R. Iannotti (Eds.), Altruism and aggression (pp.135-164). Cambridge, UK: Cambridge University Press.

Thompson, R.A. (1994). Emotion regulation: A theme of search of definition. Monographs of the Society for Research in Child Development, 59, 25-52.

Trommsdorff, G. (1993). Kulturvergleich von Emotionen beim prosozialen Handeln [Crosscultural comparison of emotions in relation to prosocial behaviour]. In H. Mandl, M. Dreher, \& H.-J. Kornadt (Eds.), Entwicklung und Denken im kulturellen Kontext (pp.325). Göttingen: Hogrefe. 
Trommsdorff, G. (1995). Empathy and prosocial action in cultural environments. A crosscultural analysis. In T.A. Kindermann \& J. Valsiner (Eds.), Development of person-context relations (pp.112-146). Hillsdale, NJ: Erlbaum.

Trommsdorff, G., \& Friedlmeier, W. (1998). Regulation of emotions and mother-child relationship: A comparison between Japanese and German preschoolers. Manuscript submitted for publication.

Trommsdorff, G., Friedlmeier, W., \& Kienbaum, J. (1991). Entwicklung von Empathie und prosozialem Verhalten bei Kindern [Relationship between empathy and prosocial behaviour in childhood]. In U. Schmidt-Denter (Ed.), Abstraktband der 10. Fachgruppentagung für Entwicklungspsychologie, 23-25.9.1991, Universität Köln (S.265). Köln: Universität Köln.

Zahn-Waxler, C., \& Radke-Yarrow, M. (1982). The development of altruism. Alternative research strategies. In N. Eisenberg (Ed.), The development of prosocial behaviour (pp.109-137). New York: Academic Press.

Zahn-Waxler, C., Radke-Yarrow, M., \& King, R.A. (1979). Child rearing and children's initiations toward victims of distress. Child Development, 50, 319-330. 